\title{
Using Structural Social Work Theory to Drive Anti-Oppressive Practice With Latino Immigrants
}

\author{
Arturo Carrillo \\ Caitlin L. O'Grady
}

\begin{abstract}
Social work practice with marginalized populations not only requires intervention to address individuals' immediate service needs, but also requires intervention to address the larger structural context that impacts well-being. Critical theoretical frameworks, such as Structural Social Work (SSW) theory, are essential in helping social workers to develop a comprehensive understanding of the manner in which social systems are intentionally designed to oppress marginalized populations, including immigrant and refugee communities. SSW serves to both understand how society's structure causes social problems and to identify how these structures must be changed in order to alleviate harm. Focusing specifically on Latino immigrants, this article presents an overview of SSW theory and discusses its relevance to social work practitioners. This SSW framework will then be applied to analyze two U.S. social systems, the labor regulatory and mental health systems, that are integrally connected to Latino immigrant well-being. Finally, drawing from two case examples of research conducted in Chicago, alternative models of practice in the realms of labor and mental health are presented. Findings from these case examples illustrate how social workers can engage in antioppressive practice when they implement interventions that promote personal healing while simultaneously challenging oppressive elements of social systems.
\end{abstract}

Keywords: Structural social work theory; labor; mental health; Latino immigrants; antioppressive practice

Hide nothing from the masses of our people. Tell no lies. Expose lies whenever they are told. Mask no difficulties, mistakes, failures. Claim no easy victories... (Cabral, 1970, p. 89)

These words of Amilcar Cabral (1970) remind us of the necessity to engage in a genuine way with those with whom we seek to work. As social workers, if we are truly to work for the emancipation and empowerment of those we serve, we must be cognizant of the challenges we are faced with in practice, including both the realities of the "client" and that of the profession. In the same way that Amilcar Cabral used his professional training to support the struggle for liberation of the people of Bissau-Guinean and Cape Verde from the colonization of Portugal, as social workers we are positioned to engage in the complex and at times turbulent work of anti-oppressive practice. Anti-oppressive practice requires that we recognize how individual well-being is integrally connected to larger social institutions. Considering that social institutions in the U.S. perpetuate systems of power, privilege, unequal access, and oppression, anti-oppressive practice intends to alleviate the negative impacts of oppressive social systems on individuals while simultaneously transforming these social structures that perpetuate oppression (Mullaly, 2007). As

Arturo Carrillo, PhD, LCSW, Saint Anthony Hospital: Community Wellness Program. Caitlin L. O’Grady, PhD, LCSW, Saint Anthony Hospital: Community Wellness Program. 
Amilcar Cabral pushes us to understand through his words, we must be honest in the complexities of engaging in anti-oppressive practice and must not claim easy victories that fall short of structural transformation.

Social work with immigrants and refugees presents an important space to engage in anti-oppressive practice. Immigrants and refugees enter a U.S. sociopolitical context where nativist sentiment and rhetoric is pervasive (Ayón, 2014; Collinson \& Diamond, 2016; Salas, Ayón, \& Gurrola, 2013). Members of these populations commonly experience multiple forms of oppression, including exploitation, marginalization, exclusion from social and civic spaces (i.e., powerlessness), pressure to assimilate to dominant cultural norms (i.e., cultural imperialism), and violence (Young, 2013). These experiences of oppression are manifested in both their interactions with U.S. social structures and in their daily interpersonal interactions (Aguilar-Gaxiola et al., 2012; Garcini et al., 2016; Raymond-Flesch, Siemons, Pourat, Jacobs, \& Brindis, 2014). The labeling of the immigrant population in reference to categories of legality and illegality is used to legitimize oppressive acts (Menjívar, 2016). Considering that experiences of oppression are central to the experiences of immigrants and refugees in the U.S., it is essential that social workers are prepared to assess the impact of oppressive structural contexts on wellbeing and to challenge oppressive social structures in their daily practice.

Focusing specifically on Latino immigrants, this article will introduce Structural Social Work, a critical social work theory. Following this theoretical overview, we will use a Structural Social Work lens to analyze the U.S. labor regulatory and mental health systems, two systems that are integrally connected to the well-being of this population. As part of this analysis, we will discuss how these systems are intentionally designed to perpetuate oppression. Finally, drawing from two case examples of research that the authors conducted in Chicago (Carrillo, 2017; O'Grady, 2017), we will discuss how social workers can practice outside of oppressive systems. Recognizing how oppressive interactions with social systems negatively impact well-being, the highlighted practice models in the realms of mental health and labor organizing are intentionally designed to promote alternative patterns of interaction. These spaces serve as refuges where community members are supported in reframing their understanding of themselves and their environments, with the aim of empowering them to advocate for structural change in their communities. After highlighting how these alternative practice models both promote personal healing and cultivate spaces of resistance, we will discuss the implications of these local level practices for the social work profession.

\section{Structural Social Work Theory and the Role of Critical Frameworks in Practice}

Critical theoretical frameworks provide an important foundation for guiding social work practice grounded in principles of social justice. Critical theoretical frameworks assist social workers in developing a comprehensive understanding of the structural context that impacts the immigrant population and provide a lens for identifying practice solutions that challenge this context. Attending to the larger structural context ensures that individuals, families, and communities are not pathologized for the challenges that they experience. A 
Structural Social Work (SSW) critical theoretical framework is of particular relevance for informing anti-oppressive practice with the Latino immigrant population. First, SSW theory provides a descriptive understanding of how oppressive dominant ideologies inform political, economic, and social systems and patterns of interpersonal interactions. Second, SSW offers a prescriptive approach for supporting individuals who have been harmed by social systems and challenging these oppressive social systems and underlying ideologies that cause harm (Mullaly, 2007). While we recognize the breadth of scholars contributing to the body of critical social work literature, we focus primarily on Mullaly's (2007) work in our overview due to the fact that Mullaly's (2007) bridge model of society is central to our subsequent analysis of both the U.S. labor regulatory and mental health systems and the presented alternative practice models.

\section{Structural Social Work Theory}

SSW, as first postulated by Maurice Moreau in Canada in 1979, was created in reaction to the "medical and disease model" which seeks to work with people in a dependent position, emphasizing change at the individual rather than the sociopolitical level. SSW seeks to focus the intervention on the direct interactions between individuals and social, political, and economic systems (Moreau, 1979). Stemming from Radical Social Work, which is grounded in socialist ideologies, SSW criticizes conventional social work for a lack of critical self-awareness and pathologizing the oppressed by opting for individual diagnosis at the expense of addressing large social problems (Mullaly, 2007). Even with the attention given to societal level concepts, SSW is meant to be a generalist model of practice for social work with individuals, families, groups, and communities, while not losing sight of the interaction between the personal and larger cultural and political forces (Mullaly, 2007).

As conceptualized by SSW, society is envisioned as a bridge structure, whereby the bedrock, or substructure, on which the bridge is erected is the ideology that underpins society. The foundation of a bridge is not visible, yet it is essential to support the structure on which it is built. The ideologies of society provide a similar foundation. The pillars holding up the bridge platform are the various social institutions created to manage society's primary functions, including but not limited to economic, political, social welfare, labor regulatory, educational, and health systems. The platform of the bridge on which the general population exists and interacts is largely defined by the lower portions of the structure. As Mullaly (2007) explains, "the substructures or foundation of society consists of a dominant ideology, which is transmitted to all members of society through the process of socialization and determines the nature of a society's institutions and the relations among its people" (p. 245). To achieve social transformation, change must happen at all levels and social workers must be ready to navigate throughout the three levels as outlined by the SSW model. Mullaly's (2007) bridge model is displayed below.

At its core, SSW is meant to be both descriptive and prescriptive. The model serves to both understand how society's structure causes social problems and to identify how these structures must be changed in order to alleviate harm. To achieve this goal, an immediate focus on relief must also be accompanied by a long-term focus on structural and institutional change. Utilizing a dialectical understanding, SSW understands that social 
welfare and social work contain opposing forces of social care and social control. Given this understanding, the focus of practice is meant to "maximize the emancipatory potential of social welfare and social work and to neutralize or minimize the repressive elements" (Mullaly, 2007, p. 238).

Figure 1. Mullaly's Structural View of Society (Bridge Model)
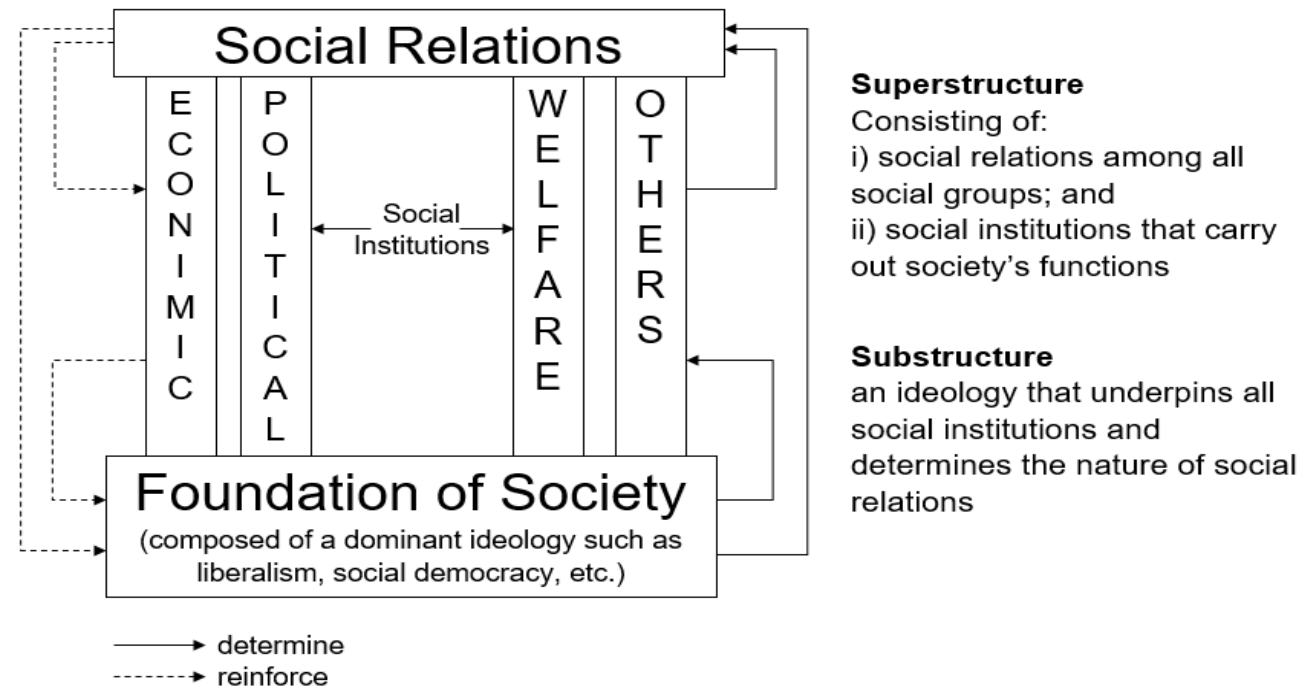

Reproduced with permission from Mullaly (2007, p. 246)

Recognizing that critical analysis of social systems is central to SSW, in the following section we will analyze two U.S. social systems through a structural lens. In particular, we will analyze both the U.S. labor regulatory and mental health systems. Based on our synthesis of the literature, we contend that not only does the Latino immigrant population have unmet needs in the realms of labor and mental health, but also that these systems are designed to perpetuate structural oppression rather than to address unmet needs.

\section{U.S. Social Systems Through A Structural Lens}

\section{U.S. Labor Regulatory System}

The labor regulatory system falls within the economic system of our society. It is intended to be the mechanism that checks the detrimental impacts of exploitation on workers by employers in their pursuit of profit and efficiency within the capitalist economic system. The labor regulatory system encompasses laws and policies that regulate workplace standards, the state and federal worker protection agencies established to enforce workplace policies (including among others, the Department of Labor, Equal Employment Opportunity Commission), and collective bargaining agreements set by labor unions. In order to understand the structural causes of the workplace exploitation on lowwage immigrant workers, an analysis of the U.S. labor system must be contextualized in relation to both the U.S. labor regulatory system and the immigration system. 
The immigration system and labor regulatory system: The connection between "illegality" and substandard working conditions. The literature has long emphasized the role of immigration policy in regulating the flow of foreign labor into the United States (Borjas, 1989; De Genova, 2005; Gomberg-Muñoz, 2011; Massey, Durand, \& Malone, 2002; Sassen-Koob, 1981). Decades of increasingly restrictive U.S. immigration policy, culminating with the passage of the Immigration Reform and Control Act of 1986, established a present day political reality in which 11.1 million people live in the United States without legal status (Passel \& Cohn, 2016). The political creation of "illegality" establishes a vulnerable and "temporary" population that is often exploited in the workplace and made to live in fear within their communities (Gleeson, 2010). The Mexican migrant community has for generations served as a continued and expendable pool of labor for the United States (De Genova, 2004). By creating a system of deportation targeting undocumented workers, the nation creates what is essentially a disposable commodity (De Genova, 2002).

Even though undocumented immigrant workers maintain many of the same legal protections as documented workers in the workplace, their undocumented status places them in a relatively powerless position. Various studies have identified that undocumented workers face a higher likelihood of experiencing wage theft (Bernhardt et al., 2009; Fussell, 2011), wage disparities (Hall, Greenman, \& Farkas, 2010; Rivera-Batiz, 1999), unsafe workplace conditions (Mehta, Theodore, Mora, \& Wade, 2002), and workplace injuries and fatalities (Orrenius \& Zavodny, 2009; Sanchez, Delgado, \& Saavedra, 2011). Substandard wages and workplace conditions plague entire industries and communities that employ a high percentage of immigrant workers (Bernhardt et al., 2009; Levin \& Ginsburg, 2000).

Among the most pervasive experiences of immigrant workers is the loss of owed wages. Violations of wage and hourly laws are commonly referred to as wage theft (Bobo, 2009). It occurs through various forms including: failure to pay minimum wage, failure to pay overtime (i.e., paid less than 1.5 times the regular rate of pay for all hours over 40 per week), "off-the-clock violations" (i.e., work not compensated before or after regular shift), meal break violations (i.e., work during break without compensation), or illegal deductions taken from workers' pay. A study by Bernhardt et al. (2009) of 4,387 workers in the three largest cities in the U.S., New York, Chicago, and Los Angeles, identified the industries with the highest rates of wage theft, as measured solely by minimum wage violations. These industries included apparel and textile manufacturing (42.6\% violation rate), personal and repair services $(42.3 \%)$, private households $(41.5 \%)$, retail and drug stores $(25.7 \%)$, grocery stores $(23.5 \%)$, security, building and ground service $(22.3 \%)$, food and furniture manufacturing, transportation and warehousing (18.5\%), restaurants and hotels (18.2\%), residential construction (12.7\%), home health care (12.4\%), and social assistance and education $(11.8 \%)$. The same analysis of minimum wage violations by demographics identifies undocumented immigrants as reporting the highest percentage of wage violations. Within this demographic, there is a marked difference by gender; nearly half $(47 \%)$ of undocumented female respondents reported minimum wage violations compared to $30 \%$ of undocumented men, by far the highest rate among workers interviewed. 
The need for and limitations of federal and state labor enforcement agencies. The relatively powerless position of vulnerable workers makes them less likely to report substandard work conditions (Fussell, 2011). As a result, there is a considerable role for federal and state regulatory agencies to ensure compliance of wage and hourly laws for all workers, including undocumented workers. At the federal level, the Department of Labor is tasked with, among other responsibilities, regulating workplace conditions. Specifically, the Wage and Hourly Division (WHD) "enforces Federal minimum wage, overtime pay, recordkeeping, and child labor requirements of the Fair Labor Standards Act" (U.S. Department of Labor, n.d.). However, analysis of the WHD has shown continued reductions in the investigative staff since its inception. In 1941 when it was first created, the WHD employed 1,769 investigators, compared to 1,544 in 1962 and 750 in 2007. Investigators have decreased despite the fact that the number of businesses covered by the WHD has seen a dramatic increase from 360,000 to 1.1 million to 7 million in the respective years (Bobo, 2009). Separate analyses demonstrate similar findings; between the years of 1975 and 2004 the number of investigators decreased by 14\% from 921 to 788 , while the number of workers covered increased by $55 \%$ and the number of businesses covered increased by $112 \%$ (Bernhardt \& McGrath, 2005). The limited availability of investigators has led the WHD to be a worker-initiated complaint driven agency instead of one designed to conduct proactive investigations (Weil, 2008). Beyond the federal labor regulatory agencies, states can establish their own labor protection agencies in order to increase the level of protections for workers. However, the enforcement capacity and role of each state agency varies widely throughout the country (Meyer \& Greenleaf, 2011).

The absence of labor unions. The erosion of union density in the private sector over the last 50 years is striking (Bui, 2015). This has had a marked impact on working standards within the United States labor market. Without union representation, workers lose the ability to use collective bargaining to increase wages, benefits, and improve working conditions. As a result, in a 44 year span the share of the nation's income taken home by the middle class has declined, with the aggregate household income having shifted from middle-income households, $62 \%$ in 1970 to $43 \%$ in 2014, to upper-income households, 29\% in 1970 compared to $49 \%$ in 2014 (Pew Research Center, 2015). The decline in union membership accounts for $35 \%$ of the falling share of workers within the middle class and explains nearly half when adding in the union equality effect (Freeman, Han, Madland \& Duke, 2015). It has also played a role in limiting upward mobility among low-income children, especially when parents are low-skilled workers (Freeman, Han, Duke, \& Madland, 2016).

Within the current labor regulatory system, various factors make it unfeasible for labor unions to organize low-wage workers. Mehta and Theodore (2005) identify the obstacles that employees and organizers commonly experience during their efforts to organize labor unions. Findings from their analysis of 25 union organizing campaigns indicated that companies engaged in a variety of legal and illegal tactics to discourage union organizing (Mehta \& Theodore, 2005). While legislative solutions such as the Employee Free Choice Act would serve to lower the hurdles for workers to unionize and would increase opportunities for collective bargaining in more workplaces, more and more states adapt "Right to Work" legislation, which purpose is to weaken union membership by making 
union dues optional by union members and prohibits union membership as a condition of employment. The limited support that unions are able to offer to low-wage immigrant workers, coupled with the shortcomings of federal and state labor regulatory agencies, point to the ineffectiveness of the U.S. labor regulatory system in protecting immigrant low-wage workers from workplace exploitation.

The psychological harm of the labor regulatory system's failings. Not only do immigrant workers have unmet needs in the realm of labor protections, but experiences of workplace exploitation have also been found to negatively impact emotional well-being. Lesniewski and Drucker (2017) conducted a mixed-methods research project that explored the psychosocial impact of wage theft on low-wage immigrant workers. Findings revealed that two-thirds of respondents were likely or highly likely to suffer from depression. Immigrant workers who took part in this study reported that they often had to take on additional jobs to compensate for lost wages and experienced psychological distress, family conflict, and nutrition and health issues as a result of working long hours and coping with financial hardships and housing instability (Lesniewski \& Drucker, 2017). Synthesizing the literature on the labor regulatory system, it is not only evident that the system fails to address the needs of immigrant workers coping with workplace exploitation, but it is also evident that the system intentionally creates an expendable workforce who is vulnerable to exploitation. Furthermore, these experiences of workplace exploitation negatively impact immigrant workers' mental health.

\section{U.S. Mental Health System}

The negative impact of workplace exploitation on emotional well-being is part of a growing body of literature exploring the effects of structural oppression on the mental health of Latino immigrants. For example, research has attributed living in a hostile, antiimmigrant political climate to mental health challenges including depression, anxiety, and chronic trauma among Mexican immigrant adults and their children in Arizona (Salas et al., 2013). Similarly, Flores et al. (2008) found that experiences of interpersonal discrimination were associated with depression among Mexican immigrant adults in California. Evidence also indicates that the experience of being undocumented in the oppressive structural context of the U.S. negatively impacts mental health. Research cites specific examples of experiences that are associated with mental health symptoms, including limited access to employment, education, healthcare, and social services; living in constant fear of deportation; and exposure to negative stereotypes about undocumented immigrants (Garcini et al., 2016; Raymond-Flesch et al., 2014).

A structural analysis of the U.S. mental health system not only indicates that oppressive social systems and discriminatory patterns of interpersonal interactions negatively impact mental health, but also that the system is intentionally designed to limit access to mental health services and inadequately address the mental health needs of Latino immigrants. In accordance with Mullaly's (2007) bridge model of society, underlying capitalist ideologies inform the development of a mental health system that ignores the impact of structural oppression on well-being and limits access to services based on an individual's ability to pay. First, the limited attention paid to the impact of structural oppression on well-being is

reflected in the dominance of what Saleebey (2005) describes as the "medical- 
psychiatric/pharmaceutical/insurance cartel" (p. 23) model of mental health. Saleebey (2005) defines this model as one in which "a group of institutions...control a particular market or social sector through a melding of their interests and exercising of their social power" (p. 23). By framing mental health in relation to biochemical responses, illness, deficits, and pathology, this biomedical model of mental health service delivery advances the interests of psychopharmaceutical companies while failing to address the structural context that impacts well-being (Saleebey, 2005). Second, according to Rylko-Bauer and Farmer (2002), the mental health system is part of the larger

...market-based [healthcare] system shaped by forces of competition, commercialization, and corporatization...The orientation is increasingly one of selling 'product' rather than providing care, to 'consumers' and 'clients' rather than to patients, with a reliance on competition to control costs and encourage 'efficiencies'. (pp. 478-479)

For underinsured and uninsured individuals who are unable to pay out of pocket for mental health services, treatment options are limited.

The structure of the mental health system results in disparate rates of mental health service access and lower quality services for Latino immigrants. There is a well-established body of literature identifying cost and lack of insurance coverage as barriers to service access (Bridges, Andrews, \& Deen, 2012; Cabassa, Lester, \& Zayas, 2007; SantiagoRivera et al., 2011). These access barriers translate to lower rates of service utilization among Latino immigrants in comparison to both non-Latino Whites and U.S.-born Latinos (Cabassa, Zayas, \& Hansen, 2006). In addition, evidence indicates that immigrant and U.S.-born Latinos are less likely than non-Latino Whites to receive depression treatment in accordance with established care guidelines, thus pointing to disparities in treatment quality (Lagomasino et al., 2005). Horton (2006) further illustrates the negative impact of the market-based care system on service quality in her case study of a mental health clinic serving primarily uninsured and Medicaid insured Latino immigrants in the northwestern U.S. Because the mental health clinic's parent hospital was facing budget difficulties due to limited reimbursement for the provision of charity care to the uninsured, the hospital placed increased demands on clinician "productivity" (i.e., meeting specified billable hours quota). In order to meet these demands, clinicians were pressured to implement practices including shortening appointment times, limiting or denying services to uninsured individuals, double booking appointments, and stopping service provision to program participants who "no showed" three appointments, meaning that they missed appointments without providing 24-hour notice (Horton, 2006). Clinicians identified these practices as conflicting with their beliefs about high quality service provision (Horton, 2006).

Within the city of Chicago, the site of the case studies highlighted in this article, research has documented similar disparities in mental health service access and quality for Latino immigrants. Over the past decade, there has been a disinvestment in publicly funded mental health services throughout the city. While there were 12 free mental health clinics operated by the Chicago Department of Public Health (CDPH) in the year 2011 (at one point 19), the number has been reduced to five currently operating clinics (Coalition to Save Our Mental Health, n.d; Lowe, 2015; Spielman, 2017). The only two bilingual 
English and Spanish CDPH clinics were among those that closed (Fecile, 2012). Furthermore, a mixed methods study surveying 2,859 primarily Latino community residents on Chicago's southwest side found that $57 \%$ of respondents identified cost, $38 \%$ identified lack of insurance coverage, and 34\% identified a lack of services in close geographic proximity as posing service access barriers. Stigma, by comparison, was reported by only $11 \%$ of those surveyed (Collaborative for Community Wellness, 2018). In addition, qualitative data from this same study indicated that when service providers do not consider the impact of structural context on well-being, they are limited in the extent to which they can truly address community residents' mental health needs (Collaborative for Community Wellness, 2018). At both the national and local levels, the mental health system contributes to and reinforces Latino immigrants' experiences of structural oppression by systematically denying access to high quality services.

\section{Challenging Structural Oppression in Practice: Empirical Case Examples}

SSW not only emphasizes the importance of assessing social systems from a critical perspective, but it also highlights the importance of challenging structural oppression. The following section will present two empirical examples of practice approaches that challenge oppressive structural contexts based on the authors' research in Chicago. The section will begin with a description of Carrillo's (2017) empirical analysis of innovative practice approaches in the labor realm and a summary of key findings from this analysis. The section will then provide an overview of O'Grady's (2017) case study of a mental health program and highlight findings pertaining to the program's anti-oppressive practice approach.

\section{Alternative Practice Model: Labor}

The emergence of the worker center movement has served as a novel approach to organizing workers in the low-wage labor sector who are largely excluded by organized labor. It is in this space that innovative strategies have developed to organize the "unorganizable."

Study methodology. The study by Carrillo (2017) was conducted as research for a doctoral dissertation, with IRB approval. The research focused on the following two research questions: 1) How are the various factors present in the lives of low-wage immigrant workers, excluded workers, and the excluded workforce, in particular, elements of personal, cultural, and structural oppression understood by the worker center organizers? 2) How does this understanding shape and determine the interventions of the worker center organizer and the maturing worker center movement in the Chicagoland area at the three different levels of society; superstructure (interpersonal), structural (social institutions) and substructural (ideologies) in support of this vulnerable workforce? Carrillo (2017) contributes to the literature by examining and developing a conceptual understanding of this organizing process through in-depth, semi-structured interviews with 18 worker center organizers at eight worker centers in the Chicago metropolitan area. Data were analyzed by the author using a modified grounded theory approach to understand the dimensions, properties, context, actions and their consequences related to the process of organizing 
vulnerable workers across a variety of low-wage industries and throughout distinct communities in the Chicagoland region.

Study findings. Interviews with the organizers provided space for an examination of the structural elements that are perceived as oppressive in the lives of the workers. The following structures are listed in the order of mentions received within the interviews: labor regulatory (governmental regulatory and enforcement agencies, labor unions, labor policy), immigration (lack of immigration reform, threat of deportation), economic (neoliberal capitalism, the fissured workplace, temp staffing agencies, the informal economy), criminal justice (incarceration, lack of rights for ex-offenders), housing (lack of housing assistance, limited affordable housing options), political (established political parties), educational (school system), welfare (social safety net programs), and health care (access to health care). Many of these structural elements were not only understood through their interconnections, which increase vulnerability to exploitation, but also added to contentious relationships of workers often along racial lines. One respondent captured this notion in the following way:

Latino workers, immigrant undocumented workers, are the preferred group for many of these factory owners. They do not... and if you think about why right. It is not knowing regulations, it is not knowing laws, it is like a very obedient workforce that does not cause problems for the boss. People do what they are told right. And it because a fear of retaliation right, fear of deportation, a fear of, if you lose your job you do not have a safety net. You cannot file for unemployment right. So, on the other end, native-born people, if they lose if they are at a place for you know a certain amount of days then they can file for unemployment right. And then the unemployment insurance goes up for the temp agency right. And then you get the factory owners and just say I don't want any Black people I want Mexicans, you know.

Although each worker center organization is unique, common features exist. Worker centers are often hybrid organizations that take on various functions, including service provisions, advocacy, organizing and formation. The organizations do not exclusively focus on workers from only one company but instead are place-based and work with employees from different employers. These are often democratic organizations, rooted in Latin American liberation movements, which employ elements of popular education. Worker centers often employ a broad agenda that involves causes outside of labor, such as education, tenant rights, and immigration-related issues, among others. They may also involve international issues and transnational work. The centers often have a small but dedicated membership that supports different functions of the organization (Fine, 2006).

Even though worker centers may be varied in their origin and function, they all are grounded in the need to organize alternative local solutions where little else exists in an effort to address the challenges faced by low-wage workers. As a result, organizers have developed strategies to address the issue of workplace exploitation throughout entire sectors of the labor market and within specific communities. These organizers employ a variety of approaches, including direct action, legal action, policy initiatives, partnerships 
with state enforcement agencies, collaborations with ally organizations, and promotion of higher workplace standards among the business community.

Understanding the function of the worker center through a structural social work lens proved to be a fruitful endeavor. As a tool to examine oppression in the lives of low-wage workers and prescriptive functions of assessing opportunities for intervention, the model resonated with the worker center organizers in this study. The findings allowed for a detailed understanding of the function that the worker center served as a space for supporting individual workers, organizing for structural change, and engaging in the ideological realm. Worker centers serve as a focal point of activity by workers who seek support on workplace related injustice. However, for workers engaging with the worker center, it also gives them access to many other types of support and possibilities for development.

Worker center organizers shared their understanding of the work through the various roles and functions they serve. At an interpersonal level, the function of the worker center is not only to provide support and attempt to offer relief for the worker, but to also conduct an assessment of other issues present in their lives so that the worker can be connected with other resources and understand how their personal experience is linked to structural oppression. The following respondent highlights an example of the understanding of structural violence as the compounding effect of various oppressive systems:

So, I know a worker who has cancer and obviously can't get Obamacare because he is undocumented, and we worked really hard to figure out what to do with him and how to get him what he needed. Before Obamacare even existed, it was more of a question of language access and like if he was trying to get special treatment, could he find the clinic to go to... all of that sort of stuff. So, I think one area of that, is access to services. Another is, and super prevalent one, is contact with the criminal justice system. Whether that is the DUI and in Chicago DUI checkpoints are almost all in black and brown neighborhoods. Whether that is the ways that individual crises mix with poverty to create criminalized communities. You know, like I grew up in an alcoholic household and I also grew up in the suburbs, so you did not see police on a regular basis. So, the ways individual crises and class intersect often leads to calls to the police because there is a fight or DUIs or drinking in public, all of that sort of stuff. Not to mention the direct attack on the workers and the direct racialized policing and that sort of stuff that you know... you are on your way home and a cop forces you up against a wall just for no reason. You know with day laborers a lot of them were living in homeless shelters and a lot of those shelters were getting closed down too.

Understanding the ties between the personal and the structural, the worker center organizer can engage with the worker in active capacity building and leadership development. The constant presence of the worker center within the marginalized communities they serve also provides the worker center with an opportunity to become the content experts on worker exploitation, and together with the worker engage in developing solutions. 
Engaging in the process of structural reform was at the heart of the worker center model, in spite of every challenge present in this undertaking. It is clear however that seeking structural reform requires the development of power. The respondents were all aware of the necessity to develop worker power and would activate their membership base in order to challenge employers and labor regulatory institutions and to reshape policy in favor of the vulnerable worker. Worker center organizers attempt to navigate three essential elements of power: social, economic, and political.

For us [in the Mexican labor movement] it was important [to understand] organizing socially, the economically, and the politically, if you handle all three, you move where you want, and you have power. If you do not handle all three you will not have power as an organization. And here [in the American labor movement] there is no power. The unions have the economic power but not political or social because in the political they are dominated. In the social, they do not do work, they do not care.

Even though challenges and limitations exist in the three areas, respondents were optimistic of the potential for a recently established coalition of worker centers to increase their organizational capacity, as well as to amplify their ability to engage in structural reform. Utilizing the popular organizing axiom, "understanding the world as it is and working towards the world as it should be," worker center organizers must be innovative, creative, resourceful, and above all, not lose sight of what is possible in order to actively support the vulnerable workers. One excellent example of this is the development of the worker cooperative as an alternative economic model, that places people before capital.

Although this study was not meant to be a thorough exploration of all the ideological elements influencing the experiences of the vulnerable worker, capitalism and/or a critique of capitalism was found to be a central ideology in the findings. As this respondent articulates:

I view my goal is developing politically conscious working class leaders and that really only happens through struggle and through struggle in a particular way that is democratic, that is where workers own the struggle and they have to kind of come to grips with the consequences of their actions, they have to come to grips with the strategy themselves and through that process become aware and conscious of capitalism, of racism of the forms of oppression that they are facing and develop leadership over time.

Furthermore, some respondents were keen to understand the dangers of organizing without a deep ideological grounding, as referenced in their critique of Alinsky-style organizing and the U.S. labor movement. Quotes from two different respondents capture this understanding:

So many problems with Alinsky in terms of race and gender and stuff like that. But the biggest critique I have is the whole like leave your ideology at the door and I think, when you do leave your ideology your values your beliefs at the door you get into a situation where, what happened with Alinsky where you organized a bunch of people to like discriminate against another set of minorities. Which you 
know, the organizing he did in the Back of the Yards, basically he does organizing to exclude black people from the area.

[The] U.S. labor movement because it has no explicit ideology, you know gets led down all these paths and that is part of the reason why we are where we are.

Although the respondents understood the necessity of grounding their organizing efforts in the ideological space of what a different world could look like, they presented a list of challenges to doing so. Challenges notwithstanding, both the potential and desire to develop an articulation of the ideological grounding exists within the worker center movement in Chicago.

\section{Alternative Practice Model: Mental Health}

O'Grady (2017) used a case study design to explore a branch of Saint Anthony Hospital's Community Wellness Program (CWP), located in Chicago, that offers mental health services exclusively to uninsured Latino immigrant adults. Operating under the purview of a community hospital and funded through the hospital's operating budget, the CWP offers mental health services in community-based satellite locations. Mental health services are offered in conjunction with a range of supportive services including family support, health education, and public benefits assistance. The branch of the CWP that was examined is located in a neighborhood with a predominantly Mexican immigrant population, and its unique focus on mental health service delivery with uninsured Latino immigrants provides an important opportunity to explore how the structural context impacting this population is addressed in practice.

Study methodology. O'Grady (2017) conducted a case study of the aforementioned branch of the CWP for her doctoral dissertation research. This case study was informed by the following research questions: 1) How do service providers and service participants describe the services that are delivered at the CWP? 2) How do service providers and service participants experience service delivery at the CWP? and 3) How does the program address the mental health needs of community residents? Using a transcendental phenomenological qualitative approach, O'Grady (2017) conducted 21 semi-structured individual interviews with service providers and mental health program participants; observed routine program activities; and collected 17 agency documents. O'Grady (2017) analyzed all data independently using an inductive open coding process to identify salient themes. Of the 10 interviews conducted with service providers, nine were conducted in English and one was conducted in Spanish, while all 11 interviews with program participants were conducted in Spanish. IRB approval was received prior to beginning research activities. Findings from this case study led to the development of a new empirical model for conceptualizing culturally competent service delivery (O'Grady, 2017). The section below will present data demonstrating how the CWP addresses community members' mental health needs through its anti-oppressive practice strategies, which is one element of the larger empirical model. Due to space limitations, only the English translation is presented for quotes from Spanish-language interviews with program participants. The second author translated all quotes from Spanish to English. 
Study findings. Data indicated that at both the level of the organization and the level of individual providers, mental health practice at the CWP challenges the oppressive structural context in which Latino immigrants are situated. At the organizational level, the CWP is intentionally designed to create an alternative space outside of the biomedical model of mental health service delivery. Within this alternative space, mental health services are free and time-unlimited; program participants may start, stop, and reinitiate services without penalty; and program participants are not assigned a DSM-V diagnosis. Service providers explicitly describe their alternative practice model as challenging structural oppression. Services are free and time-unlimited because community members have traditionally been denied access to long-term mental health services when they are unable to pay the out of pocket cost. Similarly, recognizing that program participants have commonly experienced multiple traumas that they may not be ready to explore immediately upon initiating services, the CWP's model provides the flexibility for program participants to process past trauma at a pace that feels comfortable without facing penalties for "no showing" appointments. Service providers also intentionally do not assign DSM$\mathrm{V}$ diagnoses to avoid pathologizing program participants. As one service provider stated:

When you're dealing with communities that have been oppressed, marginalized, a lot of this internalized oppression, you know, going to a clinical setting that then reinforces that by giving them diagnoses and reinforcing that yes, they need to be treated for whatever they're dealing with is very, very reinforcing of this oppressive nature.

Another service provider described that, by framing mental health challenges in the context of environmental conditions rather than in the context of symptomology, this alternative model conveys that: "We are products of our environments, not just products of our pathology."

The alternative practice model at the CWP offers service providers the flexibility to deliver services in a manner that aligns with their ideals about what high quality mental health service delivery entails:

We can meet our clients as we see absolutely fit. That means absolutely minimal paperwork. It's just a true devotion to the work being almost entirely relational, not planned out and boxed in and meeting milestones and meeting have you met your goals yet. No. That to me stands out.

As this quote illustrates, the alternative space that has been created at the CWP is largely defined by alternative patterns of interaction that challenge both traditional service interactions within the biomedical model and patterns of discriminatory interpersonal interactions within society at large. Through these alternative patterns of interaction, service providers dismantle power differentials in the therapeutic relationship; affirm individuals' strengths and provide a space where they may reclaim their self-worth; and collaboratively work with program participants to reframe the meaning attributed to past traumatic experiences.

Service providers described the practice of dismantling power differentials as one in which they convey that program participants enter the therapeutic space with a set of 
strengths and expertise. This practice of dismantling power differentials is thus integrally connected to the practice of affirming individuals' strengths and providing a space to reclaim one's self-worth. In accordance with this practice of affirming individuals' strengths, one service provider stated:

I am like the mirror. I'm just reflecting back to you what-who you are, and sometimes I might shift the mirror a little to the side, and have you see a different perspective of something, but it's still you, and that strength and that wisdom that you have within yourself that's coming through.

Recognizing that program participants are systematically denied access to social spaces, service providers described their role as offering a space where individuals can find the answers within themselves, and in so doing can reclaim their voice and self-worth that are silenced and denied within society at large. As program participants feel safe and empowered within the therapeutic space, they explore and reframe past traumatic experiences in collaboration with service providers. Central to this process is contextualizing traumatic experiences in relation to oppressive environmental conditions:

What it looks like is... starting to slowly, respectfully, question those narratives with curiosity, not defiantly, but sort of really start to explore the validity of those narratives and see if there are spaces in it where rather than taking a sort of oppression bound take on things that you can sort of insert strengths instead and say well is it that you are truly just a useless person who can't take matters into her own hands. Is that really true? Or is it that that has been imposed on you over the course of your entire life? How much of a choice did you really have in that matter and how much of a choice do you have now to start pushing back?...Then saying maybe then you didn't have a choice to push back, but maybe now you do.

Mental health program participants described the CWP's alternative practice model, and the alternative patterns of interaction that took place within that space, as promoting positive mental health outcomes. Program participants who had prior experiences with mental health services described the CWP as being different from other places where they had sought services:

So, my experience here in the program is that I first entered, and it wasn't like the others. They let me talk, or it was what I was looking for. So that caught my attention, it wasn't like the others where they say, and why did you come? No, they listened to me, they said, well, what can we talk about? Or rather they didn't demand that I talk about certain things, or about why I'm depressed, or something like that. No, with them, what do you want to begin talking about?

Within the context of this space where they felt the safety and freedom to explore the answers within themselves and process past traumatic experiences, program participants felt an enhanced sense of self-worth:

...it has helped me a lot, it is helping me a lot, because before I was, why are these things happening to me? And I didn't know why. But now I am understanding, seeing, that I had always blamed myself, that it must be something that I am doing 
wrong, or something like that. But with the passage of time...they are helping me to understand that things happen for some reason and that it is not always my fault.

Program participants also explained that as they processed past traumatic experiences and redefined how they viewed themselves, they became increasingly aware of the need to advocate for their rights within other social systems:

So, the program hasn't told me you have to do this, right, but rather in the way that they go about orienting you, you realize as a parent and as a member of the community what rights you have and what rights you don't have. So, I have learned so much. I have learned so much about everything, that I have rights, what I am able to do. And there are many parents that don't know that.

Lastly, program participants described how their personal transformation and their desire to affect change in their communities led to their involvement in community organizing initiatives. One service participant described how they became involved in community level efforts to increase Latino immigrants' access to mental health services:

...I have seen a radical change that has happened in my life, so radical. So, I said that I could continue with these steps and involve myself with helping people so that they become acquainted with [these services], so that they go and can solve their problems without having a big disruption or having more serious problems... if I saw this change in myself, I think that a thousand people are going to make this change that they so desire.

Program participants thus identified that as they integrated new understandings of themselves and their environments, this growing sense of critical consciousness empowered them to advocate for structural change in their communities.

\section{Implications}

\section{Implications for Social Work Practice}

From a SSW perspective, the examples of the Chicago worker centers and the CWP are illustrative of practice models that are situated between and span across the systemic and relational elements of Mullaly's (2007) bridge model (see Figure 2 below). Both practice models are informed by an understanding of how oppressive systemic and interpersonal interactions negatively impact the well-being of Latino immigrants in Chicago. In addition, both models have created alternative spaces that promote personal and structural transformation. At the personal level, the alternative patterns of interaction promoted within these spaces lead community members to integrate new understandings of themselves and their environments, which ultimately allows them to reclaim their selfworth. In the context of worker centers, immigrant workers are provided with a space to assert their rights in their place of employment, which in turn allows them to recover a sense of self-worth that was challenged as a result of workplace exploitation. Similarly, as program participants at the CWP engage in therapeutic encounters where their strengths and expertise are affirmed and where traumatic experiences are understood in the context of structural oppression, they redefine how they see themselves. 
This personal transformation is connected to social justice movement work focused on transforming structural contexts. At worker centers, personal healing is connected to efforts to improve workplace conditions and advocate for labor system regulatory changes through changes in policy. At the CWP, new understandings of how individuals view themselves in relation to their environment inform new ways of interacting with their communities and social systems. As community residents advocate for their rights and become involved in community organizing initiatives, these new patterns of interaction are linked to structural transformation. Not only do immigrant workers and CWP program participants become involved in structural change efforts, but the organizations themselves also challenge oppressive social systems through the infrastructure that they have developed to implement these alternative models.

Figure 2. The Bridge Model as Applied to Worker Centers and the CWP Diagram of the Worker Centers' and the Community Wellness Program's Placement within the Structural Social Work Model

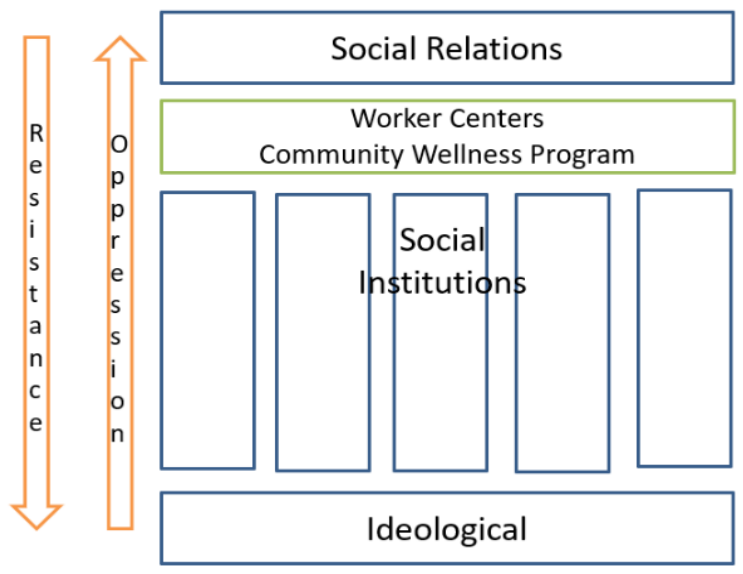

Adapted from Mullaly (2007, p. 246)

While the case examples highlighted in this article demonstrate the potential for alternative practice models to simultaneously promote personal and structural transformation, this is not to say that these models are free of challenges. Worker center organizers are aware of the enormity of the task, given the size of their organizations compared to the industries that they are looking to challenge. The largest worker center in Chicago at the time of the study only employed six organizers. Their limited organizing capacity does not allow worker centers to build the economic power necessary to effectively challenge the labor sectors they are targeting. In addition, at the CWP, the mental health program has a waiting list of approximately eight months, demonstrating that the program cannot keep pace with the demand for services. Although it is important to acknowledge these challenges, they should not be viewed as deterrents for creating alternative practice models. Recognizing that resource limitations pose challenges to the 
scope of the intervention in each of the case examples, increased investment in the creation of alternative spaces at the local level is critical for far-reaching structural transformation. Social work practitioners can play an invaluable role in advocating for the creation of these alternative spaces. Furthermore, across organizational contexts, social workers can promote personal and structural transformation by integrating into their practice an understanding of the impact of the structural context on well-being and interacting with program participants in a manner that challenges oppressive systemic and interpersonal interactions.

\section{Implications for Social Work Research}

The presented case examples highlight the importance of conducting research with marginalized populations, including the Latino immigrant population, from a SSW perspective. For the Latino immigrant population in particular, there is a growing body of literature documenting the ways in which Latino immigrants experience oppression within U.S. society. Research that fails to take into account the oppressive structural context in which Latino immigrants are situated runs the risk of pathologizing individuals, families, and communities for the challenges that they experience. In addition, research that explores how programs and organizations engage with and push back against oppressive structural contexts allows for the identification of innovative practices across realms connected to well-being. Engaging in anti-oppressive practice that promotes personal and structural transformation requires research highlighting innovative strategies for achieving this aim.

\section{Conclusion}

In this article, we have discussed the relevance of a SSW framework for understanding Latino immigrants' experiences of structural oppression. We have additionally used a SSW lens to examine how dominant ideologies inform the development of social systems that intentionally perpetuate structural oppression. Finally, we presented alternative models of practice in the realms of labor and mental health that connect interventions at the personal and structural levels. These spaces contribute to personal healing by promoting alternative patterns of interaction that support Latino immigrants in redefining how they see themselves and reclaiming their self-worth. At the same time, these interventions at the personal level empower community residents to become involved in advocacy and community organizing initiatives, which in turn promotes structural transformation. Findings suggest that when social workers are intentional in implementing interventions that both promote personal healing and challenge oppressive social systems and underlying ideologies, their efforts to change local community contexts can cumulatively translate to more far-reaching structural transformation.

\section{References}

Aguilar-Gaxiola, S., Loera, G., Méndez, L., Sala, M., Latino Mental Health Concilio, \&

Nakamoto, J. (2012). Community-defined solutions for Latino mental health care disparities: California Reducing Disparities Project, Latino Strategic Planning Workgroup population report. Sacramento, CA: UC Davis. 
Ayón, C. (2014). Service needs among Latino immigrant families: Implications for social work practice. Social Work, 59(1), 13-23. doi: https://doi.org/10.1093/sw/swt031

Bernhardt, A., Milkman, R., Theodore, N., Heckathron, D., Auer, M., DeFilippis, J., Gonzalez, A., Narro, V., Perelshteyn, J., Polson, D., \& Spiller, M. (2009). Broken laws-Unprotected workers: Violation of employment and labor laws in America's cities. Chicago, IL: Center for Urban Economic Development.

Bernhardt, A., \& McGrath S. (2005). Trends in wage and hour enforcement by the U.S. Department of Labor, 1975-2004, New York: Brennan Center for Justice.

Bobo, K. (2009). Wage theft in America: Why millions of working Americans are not getting paid-and what we can do about it. New York: The New Press.

Borjas, G. (1989). Economic theory and international migration. International Migration Review, 23(3), 457-485. doi: https://doi.org/10.1177/019791838902300304

Bridges, A. J., Andrews, A. R., \& Deen, T. L. (2012). Mental health needs and service utilization by Hispanic immigrants residing in mid-Southern United States. Journal of Transcultural Nursing, 23(4), 359-368. doi: https://doi.org/10.1177/1043659612451259

Bui, Q. (2015, February 23). 50 years of shrinking union membership, in one map. National Public Radio: Planet Money. Retrieved from https://www.npr.org/sections/money/2015/02/23/385843576/50-years-of-shrinkingunion-membership-in-one-map

Cabassa, L. J., Lester, R., \& Zayas, L. H. (2007). “It's like being in a labyrinth:” Hispanic immigrants' perceptions of depression and attitudes toward treatments. Journal of Immigrant Health, 9, 1-16.

Cabassa, L. J., Zayas, L. H., \& Hansen, M. C. (2006). Latino adults' access to mental health care: A review of epidemiological studies. Administration and Policy in Mental Health and Mental Health Services Research, 33(3), 316-330. doi: https://doi.org/10.1007/s10488-006-0040-8

Cabral, A., \& Handyside, R. (1970). Revolution in Guinea: Selected texts. London: Monthly Review Press.

Carrillo, A. (2017). Chicago's worker center movement: A structural analysis (Doctoral dissertation). University of Illinois at Chicago, Chicago, IL.

Coalition to Save our Mental Health. (n.d.). Mission and history. Retrieved from http://saveourmentalhealth.org/mission--history.html

Collaborative for Community Wellness. (2018). Uplifting voices to create new alternatives: Documenting the mental health crisis for adults on Chicago's southwest side. Chicago, IL: Saint Anthony Hospital -Center for Community Wellness.

Collinson, S., \& Diamond, J. (2016, September 1). Trump on immigration: No amnesty, no pivot. $C N N$. Retrieved from http://www.cnn.com/2016/08/31/politics/donaldtrump-immigration-speech/ 
De Genova, N. (2002). Migrant "illegality" and deportability in everyday life. Annu. Review Anthropol, 31, 419-447. doi: https://doi.org/10.1146/annurev.anthro.31.040402.085432

De Genova, N. (2004). The legal production of Mexican/migrant "Illegality". Latino Studies, 2, 160-185. https://doi.org/10.1057/palgrave.1st.8600085

De Genova, N. (2005). Working the boundaries: Race, space, and "illegality" in Mexican Chicago. Durham, NC: Duke University Press. doi: https://doi.org/10.1215/9780822387091

Fecile, J. (2012, May 9). With mental health clinic closures imminent, protesters take to the streets. HuffPost. Retrieved from https://m.huffpost.com/us/entry/1333498

Fine, J. (2006). Worker centers: Organizing communities at the edge of the dream. Ithaca, NY: ILR Press.

Flores, E., Tschann, J. M., Dimas, J. M., Bachen, E. A., Pasch, L. A., \& de Groat, C. L. (2008). Perceived discrimination, perceived stress, and mental and physical health among Mexican-origin adults. Hispanic Journal of Behavioral Sciences, 30(4), 401424. doi: https://doi.org/10.1177/0739986308323056

Freeman, R., Han, E., Madland D., \& Duke, B. (2015). Bargaining for the American dream: What unions do for mobility. Center for American Progress. Retrieved from https://cdn.americanprogress.org/wpcontent/uploads/2015/09/08130545/UnionsMobility-report-9.9.pdf

Freeman, R., Han, E., Duke, B., \& Madland D. (2016). What do unions do for the middle class? Center for American Progress. Retrieved from https://cdn.americanprogress.org/wpcontent/uploads/2016/01/11102501/UnionsMiddleClass-report.pdf

Fussell, E. (2011). The deportation threat dynamic and victimization of Latino migrants: Wage theft and robbery. The Sociological Quarterly, 52(4), 593-615. doi: https://doi.org/10.1111/j.1533-8525.2011.01221.x

Garcini, L. M., Murray, K. E., Zhou, A., Klonoff, E. A., Myers, M. G., \& Elder, J. P. (2016). Mental health of undocumented immigrant adults in the United States: A systematic review of methodology and findings. Journal of Immigrant \& Refugee Studies, 14(1), 1-25. doi: https://doi.org/10.1080/15562948.2014.998849

Gleeson, S. (2010). Labor rights for all? The role of undocumented immigrant status for worker claims making. Law \& Social Inquiry, 35(3), 561-602. doi: https://doi.org/10.1111/j.1747-4469.2010.01196.x

Gomberg-Muñoz, R. (2011). Labor and legality: An ethnography of a Mexican immigrant network. New York: Oxford University Press.

Hall, M., Greenman, E., \& Farkas, G. (2010). Legal status and wage disparities for Mexican immigrants. Social Forces, 89(2), 491-513. doi: https://doi.org/10.1353/sof.2010.0082 
Horton, S. (2006). The double burden on safety net providers: Placing health disparities in the context of the privatization of health care in the U.S. Social Science \& Medicine, 63, 2702-2714. doi: https://doi.org/10.1016/j.socscimed.2006.07.003

Lagomasino, I. T., Dwight-Johnson, M., Miranda, J., Zhang, L., Liao, D., Duan, N., \& Wells, K. B. (2005). Disparities in depression treatment for Latinos and site of care. Psychiatric Services, 56, 1517-1523. doi: https://doi.org/10.1176/appi.ps.56.12.1517

Lesniewski, J., \& Drucker, J. (2017). Economic impact and lived experience of wage theft [PowerPoint slides]. Proceedings from Urban Affairs Association 2017. Minneapolis, MN.

Levin, R., \& Ginsburg, R. (2000). Sweatshops in Chicago: A survey of working conditions in low-income immigrant communities. Chicago, IL: Center for Impact Research. Retrieved from https://www.issuelab.org/resources/364/364.pdf

Lowe, F. H. (2015, March 30). The closing of the Woodlawn Mental Health Center disrupted the lives of the Black men it served. Social Justice News Nexus. Retrieved from http://sjnnchicago.medill.northwestern.edu/blog/2015/03/30/the-closing-of-thewoodlawn-mental-health-center-disrupted-the-lives-of-the-black-men-it-served/

Massey, D. S., Durand, J., \& Malone N. J. (2002). Beyond smoke \& mirrors: Mexican immigration in an era of economic integration. New York: Russell Sage Foundation.

Mehta, C., \& Theodore, N. (2005). Undermining the right to organize: Employer behavior during union representation campaigns. University of Illinois at Chicago: Center for Urban Economic Development.

Mehta, C., Theodore, N., Mora, I., \& Wade, J. (2002). Chicago's undocumented immigrants: An analysis of wages, working conditions, and economic contributions. University of Illinois at Chicago: Center for Urban Economic Development.

Menjívar, C. (2016). Immigrant criminalization in law and the media: Effects on Latino immigrant workers' identities in Arizona. American Behavioral Scientist, 60(5-6), 597-616. doi: https://doi.org/10.1177/0002764216632836

Meyer J., \& Greenleaf, R. (2011). Enforcement of state wage and hour laws: A survey of state regulators. New York: Columbia Law School-National State Attorneys General Program.

Moreau, M. J. (1979). A structural approach to social work practice. Canadian Journal of Social Work Education, 5(1), 78-94.

Mullaly, B. (2007). The new structural social work (3rd ed.). Don Mills, Ont.: Oxford University Press.

O'Grady, C. L. (2017). Culturally competent mental health practice: A case study of an organization serving Latino immigrants (doctoral dissertation). University of Illinois at Chicago, Chicago, IL.

Orrenius, P. M., \& Zavodny, M. (2009). Do immigrant work in riskier jobs? Demography, 46(3), 535-551. doi: https://doi.org/10.1353/dem.0.0064 
Passel, J. S., \& Cohn, D. (2016). Overall number of U.S. unauthorized immigrants holds steady since 2009. Pew Research Center. Retrieved from http://www.pewhispanic.org/files/2016/09/PH_2016.09.20_Unauthorized_FINAL.pd $\underline{\mathrm{f}}$

Raymond-Flesch, M., Siemons, R., Pourat, N., Jacobs, K., \& Brindis, C. D. (2014). "There is no help out there, and if there is, it's really hard to find": A qualitative study of the health concerns and health care access of Latino "DREAMers". Journal of Adolescent Health, 55, 323-328. doi: https://doi.org/10.1016/j.jadohealth.2014.05.012

Rivera-Batiz, F. L. (1999). Undocumented workers in the labor market: An analysis of the earnings of legal and illegal Mexican immigrants in the United States. Journal of Population Economics, 12(1), 91-116. doi: https://doi.org/10.1007/s001480050092

Rylko-Bauer, B., \& Farmer, P. (2002). Managed care or managed inequality? A call for critiques of market-based medicine. Medical Anthropology Quarterly, 16(4), 476502. doi: https://doi.org/10.1525/maq.2002.16.4.476

Salas, L. M., Ayón, C., \& Gurrola, M. (2013). Estamos traumados: The effect of antiimmigrant sentiment and policies on the mental health of Mexican immigrant families. Journal of Community Psychology, 41(8), 1005-1020. doi: https://doi.org/10.1002/jcop.21589

Saleebey, D. (2005). Balancing act: Assessing strengths in mental health practice. In S. A. Kirk (Ed.), Mental disorders in the social environment: Critical perspectives (pp. 23-44). New York, NY: Columbia University Press.

Sanchez, H. E., Delgado, A. L., \& Saavedra, R. G. (2011). Latino workers in the United States 2011 Report. Labor Council for Latin American Advancement. Retrieved from http://latinosforasecureretirement.org/resources/LCLAA_Report.pdf

Santiago-Rivera, A. L., Kanter, J. W., Busch, A. M., Rusch, L. C., Reyes, W...Runge, M. (2011). Latino immigrants with depression: An initial examination of treatment issues at a community clinic. Journal of Immigrant and Minority Health, 13, 772779. doi: https://doi.org/10.1007/s10903-010-9380-2

Sassen-Koob, S. (1981). Towards a conceptualization of immigrant labor. Social Problems, 29(1), 65-85. doi: https://doi.org/10.2307/800079

Spielman, F. (2017, October 31). Health commissioner defends smaller network of mental health clinics. Chicago Sun Times. Retrieved from https://chicago.suntimes.com/chicago-politics/health-commissioner-defends-smallernetwork-of-mental-health-clinics/

U.S. Department of Labor. (n.d.). Wage and Hour Division Mission Statement. Retrieved from https://www.dol.gov/whd/about/mission/whdmiss.htm

Weil, D. (2008). A strategic approach to labour inspection. International Labour Review, 147(4), 349-375. doi: https://doi.org/10.1111/j.1564-913X.2008.00040.x 
Young, I. M. (2013). Five faces of oppression. In M. Adams, W. J. Blumenfield, C. Castañeda, H. W. Hackman, M. L. Peters, \& X. Zúñiga (Eds.), Readings for diversity and social justice ( $3^{\text {rd }}$ ed., pp. 35-44). New York, NY: Routledge.

Author note: Address correspondence to: Arturo Carrillo, PhD, LCSW, Saint Anthony Hospital: Community Wellness Program, 2826 W. Cermak Road, Chicago, IL 60623.

Email: arturocarrillojr@gmail.com 